\title{
Semantic priming over unrelated trials: Evidence for different effects in word and picture naming
}

\author{
MELANIE VITKOVITCH, ELISA COOPER-PYE, and ANTONY G. LEADBETTER \\ University of East London, London, England
}

\begin{abstract}
Two naming experiments are reported that replicated previous findings of semantic interference as a result of naming related word or picture primes three trials before picture targets. We also examined whether semantic interference occurred when the materials were reversed and picture or word primes were named before word targets. The interest in semantic interference during word naming followed a suggestion made by Humphreys, Lloyd-Jones, and Fias (1995) that word naming, like picture naming, may be reliant on a semantic route to name retrieval when the two stimuli are mixed. In contrast to their findings, we found no evidence for semantic interference during target word naming; in fact, we found facilitation from related picture primes. No priming was found for the related word prime and word target condition. The data allow us to rule out the possibility that word naming is reliant on a semantic route when mixed with pictures in this priming paradigm and to conclude that there is no clear evidence of semantic activation during word naming. We also conclude, in line with other research, that word naming and picture naming involve different processes.
\end{abstract}

When a picture is named in the presence of a related word, there is evidence for semantic interference. Naming latencies are delayed, in comparison with those in unrelated conditions. This has been demonstrated frequently with the Stroop picture-word interference paradigm, where distractor words are ignored while the picture is named (MacLeod, 1991; see also Damian \& Bowers, 2003, for a recent review). A similar semantic interference effect has also been shown by Humphreys, Lloyd-Jones, and Fias (1995). They used a paradigm in which words and pictures are again presented simultaneously but the cue for which item to name is given only after a brief interval (the postcue technique). More recently, interference from related words has also been found when the related word is presented for naming several trials before the picture target (Tree \& Hirsh, 2003). We have also found this result in a naming-to-deadline experiment, in which words and pictures alternated. Picture target naming errors were

E.C.-P. is now at the Medical Research Council, Cognition and Brain Sciences Unit, Cambridge. The data from the present experiments were presented at meetings of the Cognitive Section of the British Psychological Society (Experiment 1 at Kent, 2002, and Experiment 2 at Leeds, 2004). This research was supported by Grant RES-000-22-0109 from the Economic and Social Research Council, awarded to the first author. We thank Jennifer Stolz, Stephen Lupker, and an anonymous reviewer for their valuable comments on earlier drafts of the manuscript. We also thank Rehana Begum and Lisa Thomson for testing the participants in Experiment 1 and Anita Potton for checking the manuscript. Correspondence should be sent to M. Vitkovitch, School of Psychology, University of East London, Romford Road, Stratford, London E15 4LZ, England (e-mail: m.vitkovitch@uel.ac.uk).

Note-This article was accepted by the previous editorial team, when Colin M. MacLeod was Editor. related to earlier named words at above-chance rates (Vitkovitch, Rutter, Begum, \& Thomson, 2002). We refer to this priming effect as word-to-picture interference (word prime to target picture). Thus, there is consistency in the effect of a related word on picture naming across different paradigms.

When the word is named, instead of the picture, in the Stroop picture-word interference paradigm, little or no semantic interference is evident (e.g., Glaser \& Dungelhoff, 1984; Glaser \& Glaser, 1989; Smith \& Magee, 1980). By contrast, using the postcue technique, Humphreys et al. (1995) found semantic interference when the related word was cued for naming, instead of the picture. In the two experiments reported here, we explored whether there is any consistency to this result by examining whether semantic interference would be evident during word naming in the third paradigm, in which a related prime is named several trials before a word target.

The interfering effect of semantically related words during picture naming fits with results from other experimental paradigms demonstrating semantic competition during picture naming (e.g., Damian, Vigliocco, \& Levelt, 2001; Kroll \& Stewart, 1994; Vitkovitch \& Humphreys, 1991; Wheeldon \& Monsell, 1994). The general conclusion is that picture naming involves selecting the target representation from a set of semantic competitors. This has been accommodated within current models of picture naming (Dell, Schwartz, Martin, Saffran, \& Gagnon, 1997; Humphreys, Riddoch, \& Quinlan, 1988; Levelt, Roelofs, $\&$ Meyer, 1999). The model of Levelt et al. is a general model of language production. After structural recognition of an object and semantic activation, there is a twostage name retrieval process. The lemma is a semantically and syntactically specified lexical representation, which 
is activated prior to the phonological representation of the target picture (lexeme). It is the multiple activation of semantically related lemma representations that accounts for semantic competition in this model.

Although there is a convincing set of picture- and wordpriming studies that suggest that the phonological and semantic representations of objects and words are shared (e.g., Bajo, 1988; Bajo \& Cañas, 1989; Carr, McCauley, Sperber, \& Parmelee, 1982; Durso \& Johnson, 1979; Ferrand, Grainger, \& Segui, 1994; Glaser, 1992; Nelson, Reed, \& McEvoy, 1977; Roelofs, 2004; Theios \& Amrhein, 1989), the literature on word naming indicates that it is by no means guaranteed that single word naming requires the activation of semantics. Models of word naming have direct connections between orthographic and phonological representations, in addition to links via semantic representations (e.g., Coltheart, Rastle, Perry, Langdon, \& Ziegler, 2001; McLeod, Shallice, \& Plaut, 2000; Seidenberg \& McClelland, 1989). For example, in the dualroute cascaded model (Coltheart et al., 2001), there can be parallel activation of different routes (lexical nonsemantic, lexical semantic, and a nonlexical grapheme-to-phoneme conversion process). However, recent studies of word naming in the normal population suggest that there is a limited contribution of the semantic route (Balota, Cortese, Sergent-Marshall, Spieler, \& Yap, 2004; McKague, Pratt, \& Johnston, 2001; Monaghan \& Ellis, 2002; Moore \& Price, 1999; Shibahara, Zorzi, Hill, Wydell, \& Butterworth, 2003; Strain, Patterson, \& Seidenberg, 2002).

The separate models of word and picture naming just referred to imply that, despite sharing a semantic route to naming, word and picture naming will normally involve different processes. Picture naming is actually dependent on a process that involves selecting the target representation from a set of semantic competitors. Word naming benefits also from the connections between (or rules converting) graphemic and phonological representations, and for single words, this may be the most likely route to naming. The different theoretical accounts of naming for the two stimuli types are consistent with the conclusions drawn from the contrasting pattern of interfering effects between words and pictures in the Stroop picture-word interference studies (Glaser \& Glaser, 1989; Smith \& Magee, 1980). We noted earlier that semantic interference is evident during picture naming from a word distractor, but the reverse does not occur to any degree. Smith and Magee showed, across a range of experiments, that the time course of access to name and semantic information for the two types of stimuli differs (see also Bajo, 1988; Carr et al., 1982). Glaser and Glaser suggested that words have privileged access to the lexicon, with little or no activation of the semantic network. However, the results from the word and picture postcue naming study of Humphreys et al. (1995) suggest that there may be occasions on which word naming becomes more reliant on the semantic route. To explain the semantic interference from a related picture distractor during postcue word naming, Humphreys et al. (1995) suggested that the mix of words and pictures had resulted in a greater weight being placed on a semantic route to word naming at some point during the postcue trial. Word targets were, therefore, subject to the same kind of semantic competition as picture naming, since they were effectively named in a similar way.

There has been an interest recently in the possibility of flexibility in word processing, with a change in cognitive route according to a change in the mix of stimulus conditions. The emphasis has mainly been on a switch between lexical and nonlexical word naming, rather than on reliance specifically on a semantic route (e.g., Baluch \& Besner, 1991; Monsell, Patterson, Graham, Hughes, \& Milroy, 1992; Raman, Baluch, \& Besner, 2004; see Bajo, 1988, and Tabossi \& Laghi, 1992, for data relevant to facilitatory semantic-priming effects). A first step, therefore, is to establish whether the unusual word-naming result in Humphreys et al. (1995) generalizes to the paradigm that involves naming primes several trials before targets. The postcue and priming paradigms involve the naming of both words and pictures, whereas the Stroop picture-word experiments do not, so it is possible that the results of Humphreys et al. (1995) could replicate in the priming, but not in the Stroop, paradigm. Further evidence for semantic interference during word naming would be consistent with a reliance on a semantic route to word naming under certain conditions. A failure to replicate the wordnaming interference effect would lead to scrutiny of the postcue methodology.

In the two experiments reported here, we examined whether naming related prime stimuli before naming word and picture targets would result in semantic interference for both target types. In Experiment 1, we presented word primes and picture targets and also picture primes and word targets. In Experiment 2, we presented pictures and words as both primes and targets. In most of the conditions, intervening unrelated naming trials were presented between primes and targets.

There is a further interest in testing for semantic interference during word naming. The results may allow us to draw some conclusions concerning the likely cause or locus of the word-to-picture interference, which we expected to replicate. The cause of the interference effect is as yet unclear, although Tree and Hirsh (2003) considered the possibility of inhibition (i.e., suppression) of picture target representations, noting that the evidence for this is weak. In other work on the effect of naming picture primes on picture targets, Vitkovitch and Humphreys (1991) argued that the cause of semantic interference was residual activation remaining in semantic-to-phonological connections during the picture prime naming trials (see Wheeldon \& Monsell, 1994, for a lemma locus for semantic interference). This makes the prime a particularly strong competitor when the picture target is later named. In contrast to our recent work on picture-naming errors (Vitkovitch et al., 2002), Vitkovitch and Humphreys did not find specific interference from related word primes on picture targets, although there was evidence in the error types for a more general semantic interference effect. However, in the naming-to-deadline experiments of Vitkovitch and Humphreys, the interval (and number of 
intervening trials) between primes and targets was generally greater than those in the experiments of Vitkovitch et al. (2002) and those reported here.

In the present experiments, if we found that trials involving word targets were subject to semantic interference, implicating the semantic route to word naming, residual activation within semantic-to-phonological mappings would also become a strong candidate for the word-to-picture interference effect. The reasoning here is that evidence for semantic effects on target word naming would suggest semantic involvement during prime word naming on word-to-picture trials, given that primes and targets are not differentiated within the experiments and assuming, therefore, that word primes and word targets are similarly processed. On the other hand, a clear failure to find semantic effects during target word naming would open the possibility for other interpretations of the wordto-picture interference effect. For example, for a prime word read via a nonsemantic lexical route, residual activation within shared phonological representations after word naming could lead to semantic interference during subsequent picture naming. ${ }^{1}$

\section{EXPERIMENT 1}

Experiment 1 presented alternating word and picture stimuli, using what we will refer to as the Lag 3 paradigm (prime, filler, filler, target). One group of participants received word primes and picture targets (referred to as the word-to-picture group); a second group received picture primes and word targets (picture-to-word). We also included a Lag 1 condition (filler, filler, prime, target), as well as a control condition. Some explanation of the reasoning behind these two intervals is necessary.

The Lag 3 interval was chosen because semantic interference had been clearly demonstrated with this interval by Wheeldon and Monsell (1994; definition primes, picture targets), by Vitkovitch, Rutter, and Read (2001; picture primes, picture targets), and recently by Tree and Hirsh (2003; word primes, picture targets). By contrast, when two related stimuli are presented successively with an interval of about $4 \mathrm{sec}$ (we refer to this as $\operatorname{Lag} 1$ ), the interference effects are not always apparent (Vitkovitch et al., 2001; Wheeldon \& Monsell, 1994). Wheeldon and Monsell suggested that this may be because there are counteracting facilitatory effects. There is, after all, substantial evidence that target processing is facilitated when related primes are presented immediately before targets at an interval of $1 \mathrm{sec}$ or less (see, e.g., Neely, 1991). This includes cross-modal and within-modal word and picture priming (see Glaser, 1992, for a review). Such facilitatory priming effects in naming tasks would normally be either greatly reduced or not expected to survive intervening unrelated trials (see Masson, 1991, 1995; Neely, 1991), and hence, interference is exposed at longer lags (see Wheeldon \& Monsell, 1994, for a discussion of the potential loci and relative persistence of the interference and facilitation effects). However, in contrast to the idea of counteracting interfering and facilitatory effects, we have previously argued, on the basis of below-chance error rates, that at Lag 1 there is a temporary editing or suppression effect directed at Lag 1 (prime) stimuli (Vitkovitch \& Rutter, 2000; Vitkovitch et al., 2001). This is reduced over time, so that at longer lags interference from the prime can occur. This work follows similar research on suppression and interference effects during number fact retrieval (Campbell \& Clark, 1989).

Experiment 1 here was originally designed, along with other experiments not reported here, to look at this possible suppression effect, as well as at the expected semantic interference effect, at Lag 3. It is for this reason that primes in the Lag 1 condition, as well as in the Lag 3 condition, were included. However, the focus of this article is not on Lag 1 suppression effects or on mapping the time course of the semantic interference effect (this has been addressed by Wheeldon \& Monsell, 1994), but on the Lag 3 interference, which is clear and unambiguous. We will refer to the Lag 1 results where relevant, but we will not discuss them at length. We did not include this condition in Experiment 2.

In addition to replication of the word-to-picture interference found in earlier work (Tree \& Hirsh, 2003; Vitkovitch et al., 2002), the manipulation of interest was whether semantic interference would be evident when the materials were reversed and word targets were preceded three trials earlier by a related picture prime. This would then be consistent with the postcue results of Humphreys et al. (1995). Both groups of participants in the present experiment received the same number of alternating words and pictures, because Lupker and colleagues had shown that altering the mix of stimuli can have an effect on response time criterion if the stimuli differ in processing difficulty (Lupker, Brown, \& Colombo, 1997; Lupker, Kinoshita, Coltheart, \& Taylor, 2003; Taylor \& Lupker, 2001; see also Raman et al., 2004).

\section{Method}

Participants. Forty-eight students from the University of East London participated in this experiment. All reported English as a first language and normal or corrected-to-normal vision. Age ranged from 18 to 48 years.

Design and Stimuli. The stimuli consisted of the 36 pairs of related primes and targets used by Vitkovitch et al. (2001). All of these were pictures drawn from Snodgrass and Vanderwart (1980). The primes and targets were selected on the basis of previous error data collected in our laboratory that indicated that the prime was likely to be a strong competitor for the target. The different pairs of primes and targets were chosen so that they were unlikely to interfere with each other (e.g., bus and lorry, violin and guitar, helicopter and aeroplane). They were from a number of semantic categories (animals, musical instruments, vehicles, clothes, household items, tools, fruits, and vegetables). Unrelated filler stimuli were selected so that primes and targets could be presented in sequences of four. These were miscellaneous unrelated stimuli and were not from the same semantic categories as the experimental stimuli.

The 36 pairs of primes and targets were divided into three lists. Although all of the original materials were pictures, in this experiment, they were presented either as a printed name or as a picture, depending on the condition. In the following examples, word stimuli are given in lowercase, pictures in uppercase. In the Lag 3 word-topicture condition, the prime was presented three trials before the 
target (e.g., aeroplane, FILLER, filler, HELICOPTER). This was reversed for the picture-to-word group (e.g., AEROPLANE, filler, FILLER, helicopter). In the Lag 1 word-to-picture condition, the prime was immediately before the target picture (e.g., filler, FILLER, helicopter, AEROPLANE) and again was reversed for the picture-to-word group (e.g., FILLER, filler, HELICOPTER, aeroplane). In the control condition, there was no prime, but an extra unrelated picture was used (e.g., filler, FILLER, filler, AEROPLANE or FILLER, filler, FILLER, aeroplane).

The three lists of stimuli were rotated across the three conditions for both groups, so that no participant saw the same stimulus more than once and so that each prime and target pair appeared in every condition. Each participant therefore responded to 36 sets (trials) of four stimuli, 12 from each condition, but these were presented in a different random order to each participant. Although the sequences of stimuli were randomized in groups of four, the participants were not explicitly informed of this; they were told simply that they would see alternating pictures and words and that they should name each stimulus as quickly and as accurately as possible.

Procedure. The PsychLab software developed by Bub and Gum (1990) was used to present the stimuli on a Macintosh Centris computer and to record the naming latencies. Each stimulus was presented as a black outline drawing or as a word in the center of a light gray window and remained on the screen until the participant responded. There was then a $4-\mathrm{sec}$ interval before the next stimulus. The participants spoke their response into a handheld microphone, which triggered the millisecond timer. ${ }^{2}$ The experimenter noted any naming errors, hesitations, or failures of the equipment. The participants were given practice trials, which consisted of 12 alternating pictures and words (three sequences of four stimuli), which were not used in the experiment.

\section{Results}

Median target naming latencies were calculated for each participant for each condition, excluding incorrect responses and spoiled responses (cases in which the participant hesitated or cases of failed timing). Target latencies were also excluded for cases in which the participant misnamed the prime, although this occurred only in the pictureto-word group on $9 \%$ of the prime trials in the Lag 3 and Lag 1 conditions. By comparison, in the control condition, the participants made errors to $13 \%$ of the unrelated (prime) pictures, but this increase in error rate was due to errors on two unrelated pictures in particular. The participants did not make errors to primes in the word-to-picture group.

Table 1 gives the mean of the participant median target latencies for each condition, for the word-to-picture and picture-to-word groups. It also gives three different error rates for each condition: prime-related errors, other errors, and the percentage of spoiled responses. The primerelated errors refer to cases in which the target was misnamed with the name of the semantically related prime; in the control condition, a prime-related error was also scored when the participant misnamed the target with the relevant, although unseen, related prime. The other target errors consisted mainly of semantic errors, which included basic level competitors, superordinate terms, and a few don't know responses.

Unsurprisingly, target-naming latencies, error rates, and spoiled responses were higher in the word-to-picture group than in the picture-to-word group. Of greater interest, the pattern of latencies across conditions was different for the two groups, with shorter latencies in the Lag 3 and
Table 1

Experiment 1: Means and Standard Deviations (SDs) of Median Naming Latencies (in Milliseconds) and Error Rates (in Percentages) for Each Semantic Priming Condition

\begin{tabular}{lrrrrrr}
\hline & \multicolumn{2}{c}{ Latency } & & \multicolumn{3}{c}{ \% Errors } \\
\cline { 7 - 8 } \cline { 5 - 7 } Target & $M$ & $S D$ & & Prime Related & Other & Spoiled \\
\hline Picture targets & & & & & & \\
$\quad$ Control & 1,005 & 225 & & 2.4 & 8.3 & 2.4 \\
Lag 1 & 1,033 & 302 & & 3.5 & 8.3 & 4.2 \\
Lag 3 & 1,096 & 299 & & 6.3 & 7.6 & 2.4 \\
Word targets & & & & & & \\
Control & 734 & 103 & & 0.0 & 0.0 & $<1.0$ \\
Lag 1 & 696 & 87 & & 0.0 & $<1.0$ & 2.1 \\
Lag 3 & 720 & 93 & & 0.0 & $<1.0$ & 1.7 \\
\hline
\end{tabular}

Note-In Experiment 1, all picture targets were preceded by word primes, and all word targets were preceded by picture primes.

Lag 1 picture-to-word experimental conditions than in the control condition. For the word-to-picture group, latencies were longer in the Lag 3 and Lag 1 conditions than in the control condition.

An initial split-plot ANOVA with one between-subjects variable (group) and one within-subjects variable (prime condition) confirmed that the word-to-picture group had longer target latencies than did the picture-to-word group $\left[F(1,46)=1,081.97, M S_{\mathrm{e}}=103,337, p<.001\right]$. Using the Greenhouse-Geisser correction to the degrees of freedom due to sphericity violations, the effect of conditions was not significant $\left[F(1.44,66.23)=2.04, M S_{\mathrm{e}}=18,313\right.$, $p=.14]$, but the interaction between the two factors approached significance $\left[F(1.44,66.23)=2.59, M S_{\mathrm{e}}=\right.$ $18,313, p=.09] .^{3}$

Given the indication of an interaction between group and prime conditions and the disparity between variances across groups, the planned comparisons of experimental conditions against control conditions were conducted using the error terms from separate ANOVAs for each group of participants.

Word-to-picture group. Dunnett's test was used to compare each experimental condition against the control condition, with alpha set at .05 (critical difference $=$ 74.57). Target picture latencies were significantly longer in the Lag 3 condition than in the control condition. The comparison of Lag 1 against the control condition was not significant.

Both prime-related and other errors were sufficient for analysis. Using number of errors as the dependent variable, for the prime-related errors, the main effect of conditions was not significant $\left[F(2,46)=2.07, M S_{\mathrm{e}}=0.65\right.$, $p=.14]$. However, the comparisons of each experimental condition against the neutral condition, using Dunnett's test (with alpha set at .05), showed that there were significantly more prime-related errors in the Lag 3 condition than in the neutral condition (critical difference $=$ 0.38 , actual difference $=0.46$ ). There was no difference between the Lag 1 and the neutral condition (actual difference $=0.13$ ), although the Lag 1 prime-related error rate was slightly higher than the control error rate. 
There were no differences in error rates across conditions for the other errors $\left[F(2,46)=0.06, M S_{\mathrm{e}}=0.98\right.$, $p=.95]$.

Picture-to-word group. For this group of participants, Lag 3 and Lag 1 word target latencies were shorter than in the control condition. Using Dunnett's test (alpha $=.05$ ), these effects were found to be significant (critical difference $=14.18$, actual difference $=14.79$, for Lag 3 ).

Word-naming errors were less than $1 \%$ in all conditions and, therefore, were not analyzed.

\section{Discussion}

For the word-to-picture group, naming latencies were significantly longer in the Lag 3 condition than in the control condition, and mean latencies were longer in the Lag 1 condition than in the control condition, although not significantly so. We will not discuss the Lag 1 results in detail, for the reasons given earlier. There were also significantly more prime-related errors in the Lag 3 condition than in the control condition. This was not the case for other semantic errors. Therefore, the results from this design are consistent with our own data from the namingto-deadline task, which analyzed error rates as a function of lag (Vitkovitch et al., 2002), and with the interference effect found by Tree and Hirsh (2003).

In addition to replication, the aim of this experiment was to provide a test of whether words and pictures are named in the same way in this mixed stimulus design, both reliant on the same semantic route to name retrieval. We reasoned that if this were so, word naming should also be subject to semantic competition from Lag 3 picture primes. However, the pattern of data for the word-to-picture group and the picture-to-word group was different. In contrast to the Lag 3 interference found for the picture targets, facilitation was evident for the word targets. For the Lag 1 and Lag 3 word target conditions, naming latencies were significantly shorter than those in the control condition.

One possible difficulty in interpretation of the response time results is the absence of errors for word naming (Pachella, 1974). Analyses of speed-accuracy functions indicate that there can be a considerable change in response time associated with very small changes or nonexistent error rates; in the latter case, Pachella states that response times become uninterpretable. The changes in response time could indicate a decision to speed up or slow down responses under certain conditions. Although we cannot completely dismiss this problem of interpretation, we think it more likely that the words used in this experiment, all of which denoted common objects, were relatively easy to name and that naming latency is simply a more sensitive measure. There is no evidence for interference from related picture primes during word naming. Our preliminary conclusion is that word naming is not vulnerable to semantic competition in the same way that picture naming is. It follows that participants have not disengaged or attenuated other routes to word naming, so that they are reliant, as picture naming is, on a semantic route.

In Experiment 1, the critical interaction between group and prime condition was not significant. In Experiment 2, we aimed to replicate the different pattern of results for the word-to-picture and picture-to-word Lag 3 conditions. These conditions were tested within subjects, to increase the power to detect the interaction between prime relatedness and target type. Furthermore, we sought to replicate the facilitation effect for the Lag 3 picture-to-word conditions. A facilitation effect lasting over two unrelated trials was not anticipated, as we made clear in the introduction to this experiment. It therefore requires replication before any interpretation can be made.

\section{EXPERIMENT 2}

Experiment 2 included a replication of the Lag 3 related and unrelated word-to-picture and picture-to-word conditions, now presented to a single group of participants. Lag 1 conditions were not included, for the reasons given earlier. We increased the sample size in Experiment 2 from 24 to 40 participants. The effect sizes for the prime relatedness manipulation in Experiment 1 were 0.38 for the word-to-picture group and 0.36 for the picture-toword group. The power to detect each of these effects, based on testing 40 participants (one-tailed), was .78 and .74 , respectively. With improvement in design in Experiment 2 and an increased practice session, we expected that a power of around .80 would be achieved for each specific comparison of related and unrelated prime conditions. In addition to these planned comparisons, we will report the test of the critical interaction between prime relatedness and target type from the ANOVA statistic.

We also included within-modality priming conditions. A second group of participants was presented with related and unrelated picture-to-picture conditions and related and unrelated word-to-word conditions. It was not possible to select a sufficient number of prime and target stimuli to allow testing all the factors as within-subjects manipulations, and so within- and cross-modality priming was tested between subjects. Each group of participants received four different conditions (see below), but they had the same number of pictures and words. This minimized the possibility of a change in response time criteria across groups due to a change in the mix of stimuli (Chateau \& Lupker, 2003; Lupker et al., 2003; Taylor \& Lupker, 2001). Filler stimuli (the two intervening unrelated trials) were held constant across conditions.

In previous work (Vitkovitch et al., 2001), we have demonstrated picture-to-picture semantic interference, using the Lag 3 design. Although this was for a pure block of pictures, we expected the picture-to-picture interference effect to generalize to the present mixed word and picture design. Of particular interest, though, was whether semantic facilitation would not only replicate in pictureto-word conditions, but also be evident in word-to-word conditions. This pattern of results would be most indicative of semantic processing during word naming.

\section{Method}

Participants. Eighty student participants from the University of East London were recruited as volunteers. The age range was similar 
to that in Experiment 1. All reported normal or corrected-to-normal vision and English as a first language. Upon further questioning, 12 participants also reported being bilingual. Six participants were subsequently excluded due to recording problems (see the Results section), but these participants were replaced. The participants were paid $£ 3$ as a contribution to travel expenses. Some participants also took part as a requirement for course work.

Design and Stimuli. Prime relatedness (related or unrelated) and target type (picture or word) were tested as within-subjects factors. Four lists of materials were prepared to represent the four withinsubjects conditions. All prime and target stimuli were selected from the Snodgrass and Vanderwart (1980) picture set, so that both could appear as words and pictures. The within-modality group of participants was tested on picture-to-picture related and unrelated conditions and word-to-word related and unrelated conditions, using the four lists of materials. The cross-modality group received word-topicture related and unrelated conditions and picture-to-word related and unrelated conditions, with the same four stimuli lists.

Each of the four lists consisted of 12 sequences of four stimuli (a prime stimulus, two filler stimuli, and a target stimulus). The prime and target stimuli were from the same semantic category and included some pairs from Experiment 1. Each list consisted of exemplars from a range of semantic categories, with categories matched as closely as possible across lists (animals, vehicles, musical instruments, clothes, furniture, kitchen utensils, tools, fruits, and vegetables). There were also some miscellaneous related items (e.g., flower and leaf, clock and watch, sun and moon). On the basis of a separate rating study for the prime and target pairs, the lists were equated for visual similarity between prime and target, using a range of values. The lists of prime and target pairs are given in the Appendix.

Unlike in Experiment 1, the pictures and words could not be presented in a simple alternating manner, because of the inclusion of the within-modal group, for which the prime and the target were necessarily of the same modality. To ensure that both the within- and the cross-modal groups had the same number of pictures and words, the fillers were controlled. Each target in each of the four lists of 12 stimuli was assigned (randomly) a pair of unrelated fillers. The fillers were miscellaneous objects or the printed names of objects from the remaining unused stimuli of the Snodgrass and Vanderwart (1980) set or the printed names of objects from the Cycowicz, Friedman, Rothstein, and Snodgrass (1997) picture set. They were chosen so that they were, as far as possible, unrelated to the set of primes and targets and unrelated to the other filler stimuli. The pairs of fillers were randomly selected, but they were both words, both pictures, word and picture, or picture and word, remaining so throughout. There were three of each of these filler pairs in each list.

In the unrelated conditions, for the relevant list, the primes were reallocated to the targets randomly, with the restriction that they were indeed unrelated and that, as with related pairs, there was no initial phonological overlap between the prime and the target. The four lists of materials were rotated across the four within-subjects conditions, so that each list appeared in each condition and no stimulus was seen more than once by any participant. There were four different rotations of stimuli.

Procedure. There were 6 practice trials (i.e., 6 sequences of four stimuli), and these items were a mix of words and pictures. They were miscellaneous objects or object names. Following this, the participants received the 48 experimental trials in a different random order (12 sequences of four stimuli for each of the four conditions). They were randomly assigned to either within- or cross-modal groups and to one of the four rotations (with the restriction that there was an equal number of participants in each rotation).

The stimuli were positioned centrally one at a time on the screen of a PC as either outline drawings or lowercase words (the change in equipment from Experiment 1 was due to a change in laboratory over time). Each item remained on the screen for a period of $4 \mathrm{sec}$, with a $2-\mathrm{sec}$ interval before the next trial. The participants sat approximately $2 \mathrm{ft}$ away from the screen, and they were requested to name the stimulus, whether picture or word, as quickly and accurately as possible. They held a microphone close to their mouth, and the naming latency (from presentation of the stimulus) was recorded. The program for presentation of the stimuli was written in Visual Basic, using calls to the Windows Application Program Interface to record the naming response in a sound file. After their response and within the 4-sec interval, the experimenter keyed in whether the response was correct or not, noting separately the nature of this. The experimenter also keyed whether there was a hesitation or stutter. After the experiment, the participants completed a brief questionnaire, which included a series of questions designed to assess whether they had noticed any patterns in the stimuli, whether they had tried to predict future stimuli, and whether they had related stimuli to earlier named stimuli.

\section{Results}

As in Experiment 1, median target naming latencies were calculated for each participant, for each condition, excluding incorrect responses and spoiled responses (cases in which the participant hesitated or cases of failed timing or failure of the experimenter to record participant accuracy). Target response times were also excluded when the prime had been incorrectly named $(8.9 \%$ for pictureto-word conditions and $7.3 \%$ for picture-to-picture conditions; $<1 \%$ for word-to-picture and word-to-word conditions).

On inspection of the data, it became apparent that latencies were shorter in Experiment 2 than in Experiment 1, indicating a relatively sensitive threshold for detecting sound in the sound wave in this second experiment. In particular, the median latencies of a few participants were abnormally short, probably due to the proximity of the microphone to the lips and/or a nonrandom sound disturbance prior to response (e.g., a noise of the lips). Six outliers were identified using exploratory data analysis, and 6 replacement participants were tested.

Table 2 gives the mean of the participant median target latencies and error rates for each condition, for the withinmodal and cross-modal groups.

Initial two-factor ANOVAs showed that the critical interaction between prime relatedness and target type (picture or word) was significant for both the within-modal groups $\left[F(1,39)=14.63, M S_{\mathrm{e}}=5,094, p<.001\right]$ and the cross-modal groups $\left[F(1,39)=4.53, M S_{\mathrm{e}}=7,555\right.$, $p=.040]$. There were no interactions with the rotation of materials $(F \mathrm{~s}<1.5)$.

Experiment 2 had been designed to allow specific comparisons of related and unrelated conditions, with a particular interest in following up the picture-to-word facilitation effect in Experiment 1. Therefore, four specific comparisons were made for the within- and cross-modal conditions. Word target naming latencies were significantly shorter when a participant had previously named a related prime picture than when he or she had named an unrelated prime picture $[t(39)=2.03, S E M=10.51$, $p=.025$, one-tailed; effect size $=0.32]$. This was not the case for word targets preceded by word primes $[t(39)=$ $0.39, S E M=16.58, p=.69$; effect size $=0.06]$. By contrast, latencies were longer for picture targets preceded by 
Table 2

Experiment 2: Means and Standard Deviations (SDs) of Median Naming Latencies (in Milliseconds) and Error Rates (in Percentages) for Cross-Modal and Within-Modal Conditions

\begin{tabular}{|c|c|c|c|c|c|}
\hline \multirow[b]{2}{*}{ Target } & \multicolumn{2}{|c|}{ Latency } & \multicolumn{3}{|c|}{$\%$ Errors } \\
\hline & $M$ & $S D$ & Prime Related & Other & Spoiled \\
\hline \multicolumn{6}{|c|}{ Cross-Modal Targets } \\
\hline Picture target & & & & & \\
\hline Related & 972 & 254 & 4.6 & 12.0 & 6.6 \\
\hline Unrelated & 907 & 282 & 3.0 & 10.2 & 4.8 \\
\hline \multicolumn{6}{|l|}{ Word targets } \\
\hline Related & 590 & 141 & $<1$ & $<1$ & 1.9 \\
\hline Unrelated & 611 & 129 & $<1$ & $<1$ & 1.7 \\
\hline \multicolumn{6}{|c|}{ Within-Modal Targets } \\
\hline Picture target & & & & & \\
\hline Related & 891 & 248 & 1.9 & 10.8 & 7.9 \\
\hline Unrelated & 826 & 262 & 2.7 & 12.9 & 6.2 \\
\hline \multicolumn{6}{|l|}{ Word targets } \\
\hline Related & 575 & 166 & $<1$ & $<1$ & 2.7 \\
\hline Unrelated & 568 & 174 & $<1$ & $<1$ & 1.7 \\
\hline
\end{tabular}

Note-In cross-modal conditions, all picture targets were preceded by word primes, and all word targets were preceded by picture primes. In within-modal conditions, all picture targets were preceded by picture primes, and all word targets were preceded by word primes.

a related prime word than for those preceded by an unrelated prime word $[t(39)=3.07, S E M=21.21, p=.002$, one-tailed; effect size $=0.49]$ and also for picture targets preceded by picture primes $[t(39)=2.35, S E M=27.65$, $p=.012$, one-tailed; effect size $=0.37]$.

Both prime-related and other errors were sufficient for analysis for picture target conditions only. Prime-related errors were not normally distributed, though, and were analyzed using nonparametric analysis. There were no prime-related differences between related and unrelated picture target conditions, for either word-to-picture or picture-to-picture conditions $[Z<1.5]$. For the other errors, the effect of relatedness was not significant, for either the within- or the cross-modal groups $\left(F_{\mathrm{S}}<1.5\right)$.

\section{Discussion}

Experiment 2 included a replication of the word-to-picture and picture-to-word conditions from Experiment 1, using a within-subjects design to increase the power to detect the interaction between prime relatedness and target type. The interaction between these two factors was significant, for both the within- and the cross-modal priming groups. These results support the conclusion that the processes of naming a picture and naming a word are different; semantic interference was apparent during object naming, but not during word naming.

Experiment 2 was also designed with sufficient power to detect differences between specific priming conditions. We replicated the picture-to-word facilitation effect, which was unexpectedly found in Experiment 1. This same effect was not evident for word-to-word conditions. Overall, the planned $t$ test comparisons support the existence of interference when a picture target is named after a related prime stimulus (regardless of prime modality), facilitation when a word target is named after a picture prime, and no effect when a word target is named after a word prime. The semantic interference effects during picture naming were as predicted. How should the facilitation from picture primes during target word naming be interpreted?

Semantic facilitation is usually attributed to preactivation of related target representations. This can occur either as a result of an automatic process (e.g., spreading activation within a semantic network) or, in the case of primetarget intervals longer than about $250 \mathrm{msec}$, as the result of a more controlled process, such as the development of a set of expected stimuli (Neely, 1991; Posner \& Snyder, 1975; Thompson-Schill, Kurtz, \& Gabrieli, 1998). The picture prime could preactivate semantic, orthographic, or phonological representations for the word targets. It might also be expected that the picture prime would preactivate target representations in the picture-to-picture related condition, leading to some reduction in the interference from the related prime stimulus (see the earlier mention of counteracting interference and facilitation effects operating at different loci within the picture naming system; Wheeldon \& Monsell, 1994). The effect size for the picture-to-picture condition was a little weaker, when compared with the effect size for the word-to-picture condition $(0.37$ vs. 0.49$)$, possibly the result of counteracting effects, although we cannot firmly establish this.

There was no facilitation effect in the word-to-word condition, and in fact, target word latencies were slightly longer in the related prime condition than in the unrelated condition, although not significantly so. The experiment was designed with increased power to detect differences between related and unrelated conditions. We know from other work on naming that facilitatory word-to-word semantic priming can occur when the prime and the target are consecutive (e.g., Bajo, 1988; Bajo \& Cañas, 1989; Carr et al., 1982; see also Joordens \& Besner, 1992, for weak facilitation over one intervening trial). If there was any facilitatory priming from the related prime in the present word-to-word condition, it may not have been as long-lasting or as strong as any such priming from the related picture in the picture-to-word condition. There are some reports that picture primes can be more effective than word primes when primes and targets are presented consecutively (Carr et al., 1982; McCauley, Parmelee, Sperber, \& Carr, 1980; but see Bajo, 1988; Lupker, 1988). Or if the facilitatory priming over two unrelated trials in this experiment was the result of a controlled process, it may be easier to orient toward a particular category or to generate an expectancy set from a picture prime than from a word prime. In the postexperimental questionnaire, two thirds of the participants did report trying to anticipate subsequent stimuli-for example, whether it would be a word or a picture, or an animal. However, priming over two unrelated trials is an unusual result for naming tasks, even for a controlled process (Becker, Moscovitch, Behrmann, \& Joordens, 1997; Masson, 1991, 1995; Neely, 1991). We will discuss picture-to-word facilitation in the General Discussion section.

Some comment on the Experiment 2 error rate is necessary. Once again, there was an absence of errors in the 
word-naming conditions, but we have already discussed this in the context of latency differences in Experiment 1. For the picture-naming data, in the within-modal conditions, there was a trend toward an increase in error rate in the unrelated conditions, in comparison with the related conditions, whereas latencies were longer in the related conditions. However, the differences in error rate across conditions were not significant, even when the primerelated and the other errors were combined, so we think it unlikely that there was a speed-error trade-off.

A possible explanation for the lack of prime-related errors in the picture-related conditions is that there was a weakening of the competitor status of the primes across experiments. Errors are more likely when the prime is a particularly strong competitor to the target. In Experiment 1 , primes were chosen on the basis that, in previous experiments emphasizing speed, the target pictures were often misnamed with the prime names. There was, therefore, a good possibility that the occasional error would occur. By contrast, in Experiment 2, with the increase in lists of items for rotation across four conditions, some reorganization and addition of primes and targets were required. Primes were not necessarily as strong a competitor to their targets as in Experiment 1. In both experiments, effects were found for the more sensitive latency data.

We are confident, therefore, that we have replicated the word-to-picture semantic interference in Experiment 1 and, furthermore, have demonstrated similar semantic interference effects when the prime is a picture. By contrast, word naming is not vulnerable to semantic competition from primes at Lag 3 but can be facilitated by a picture prime.

\section{GENERAL DISCUSSION}

Experiments 1 and 2 used a controlled word- and picture-priming design and demonstrated semantic interference from word and picture primes named three trials before picture targets. This replicates the results from our earlier work using a naming-to-deadline paradigm (Vitkovitch et al., 2002), the recent results of Tree and Hirsh (2003), and the results of experiments using pure blocks of pictures (Vitkovitch et al., 2001). By contrast, there is no evidence for interference during word naming. This allows us to reject the proposal we specifically tested, that both words and pictures may be reliant on a semantic route to naming when mixed together, with both stimuli types vulnerable to semantic competition (Humphreys et al., 1995).

The presence of a statistical interaction between prime relatedness and target type in Experiment 2, for both within- and cross-modal groups, supports the hypothesis that different processes operate for word and picture naming. The pattern of effects fits with the understanding that picture naming involves selecting the target representation from a set of semantically related competitors but word naming does not. Current models of word naming do include a semantic route to naming, but this is in addition to direct connections between orthographic and phono- logical representations (e.g., Coltheart et al., 2001). Our results imply that these other routes to reading have not been disengaged or attenuated in the present experiments. Southwood and Chatterjee (1999) compared the objectnaming and word-reading errors of a deep dyslexic patient and suggested that activation of the direct lexical and grapheme-to-phoneme conversion route in parallel with the semantic route guards against semantic errors during word reading. The present results are at least consistent with this proposal. Note that the data are inconsistent with the concept of suppression/inhibition of target representations as a result of prime processing. This is a possible interpretation of the original word-to-picture results (see Tree \& Hirsh, 2003). Suppression of shared target representations should lead to interference effects during both word and picture processing.

The different pattern of effects for words and pictures is similar to results from the Stroop picture-word interference paradigm: Words interfere with pictures, but pictures hardly interfere with word naming (Glaser \& Dungelhoff, 1984; Glaser \& Glaser, 1989; Smith \& Magee, 1980). However, the word-naming data contrast with the results of the postcue technique: Humphreys et al. (1995) found semantic interference from a related picture distractor during word naming. There are two possibilities. Either there is some aspect of the postcue methodology that causes a reliance on the semantic route to word naming, or the postcue word naming result reflects some other process. For example, relative to the Lag 3 paradigm, there is arguably greater uncertainty as to the naming of the target stimuli in the postcue paradigm. This might reduce the possibility of participants' preparing themselves for the most efficient route for word naming and encourage them to adopt a single (semantic) route for naming all stimuli. Or semantic interference effects for word targets are a result of a priming of the semantic route during the postcue interval (see Humphreys et al., 1995). However, Dean, Bub, and Masson (2001) have recently argued that semantic interference effects evident in the postcue paradigm are not due to the activation of mappings between semantic and phonological representations. Instead, they interpret the results within the framework of selective attention models, arguing that the interference effects emerge due to difficulties in integrating related target and postcue attributes within memory. We are currently investigating this challenge to the postcue results and hope to resolve the discrepancy between the present word-naming results and the postcue results.

Finally, we will consider the facilitation during target word naming and whether this has implications for understanding the word-to-picture interference. On the assumption that processing would be the same for word prime trials and word target trials, we reasoned that evidence for semantic-priming effects during target word naming might be consistent with activation remaining in a semantic pathway during prime word naming in word-to-picture trials. Such activation might be the cause of subsequent interference during picture naming, as has been claimed for picture-to-picture effects over longer intervals (Vit- 
kovitch \& Humphreys, 1991). We have now rejected the possibility that words are reliant on a semantic route to naming, but as we have pointed out above, this does not rule out activation of this route in conjunction with other routes to word naming. The unexpected result, consistent over both experiments, of a semantic facilitation effect during word naming (picture-to-word) requires us to consider this possibility. However, it is possible to interpret this result without drawing the conclusion that a semantic route was implicated in word naming. For example, the related picture prime could preactivate target orthographic representations or generate a set of expected orthographic representations (see Neely, 1991). The target words could be named using orthographic-to-phonological connections. More compelling evidence for the involvement of a semantic route to word naming would be word-to-word priming effects.

In the Discussion section of Experiment 2, we suggested that if there is any facilitatory semantic priming of the word target from naming the word prime, it may be weak or transitory, in comparison with the priming effect of pictures in the picture-to-word condition. It is notable that semantic priming effects were limited to the conditions that included pictures. If activation remained in the prime word semantic pathway (activated in parallel with other routes to word naming), we would expect to observe semantic priming effects for naming latencies in the word-to-word conditions. Unless one wants to argue that counteracting facilitatory (facilitation of word target) and interfering (from activation remaining in word prime representations) effects actually cancel each other out in the word-to-word condition, the simplest way to interpret the comparable target-naming latencies for related and unrelated conditions is in terms of a lack of power to detect differences, an absence of lasting priming effects, or a minimal contribution of the semantic route to word naming. In Experiment 2, we increased the power to detect relatedness effects, and effects were present in three out of the four sets of priming conditions. Therefore, returning to consider word-to-picture interference, on balance we think that the data are not consistent with the suggestion that the interference is the result of activation remaining in semantic to phonological connections activated during word naming.

Two alternative explanations for the word-to-picture interference effect are as follows. The effect may be caused by the activation of semantics occurring after the word prime is named (Bajo, 1988; Masson, 1995; Smith \& Magee, 1980). This activation may remain within the system, causing interference when the picture target is later named. Alternatively, word-to-picture interference may be due to residual activation remaining in shared phonological representations over two intervening trials (see the introduction). A phonological locus for semantic interference has also been considered a possibility in the Stroop picture-word paradigm (see Damian \& Bowers, 2003) and by Humphreys et al. (1995) in the context of the postcue experiments. We are addressing each of these possibilities.
We are unable in the present experiments to provide a conclusive answer as to why there is a picture-to-word facilitation effect over two unrelated trials. Masson (1991, 1995) has demonstrated that unrelated intervening trials can disrupt the effect of a related prime for automatic priming processes for words and has favored a distributed memory account of priming. We have suggested that the facilitatory priming in the present experiments may reflect a controlled process, but even so, one would not normally expect participants to be able to maintain activation of a set of expected stimuli or to maintain orientation toward a category over two unrelated trials (see Neely, 1991). However, in the present experiments, it was the case that the filler stimuli were, on the whole, miscellaneous objects that did not have well-defined categories, and so it is possible that these stimuli did not cause a shift in orientation away from the prime category. The picture-to-word facilitation effect requires further study. A manipulation of the nature of filler stimuli and the inclusion of neutral primes would be a starting point.

From the experiments reported here, we conclude that the naming of related words slows the subsequent naming of pictures but that the naming of related pictures can facilitate the subsequent naming of words. Presenting a mix of the two types of stimuli within a block of naming trials does not, in itself, encourage a reliance on a semantic route to word naming. Instead, the Lag 3 paradigm has provided data consistent with results from the Stroop picture-word interference paradigm, showing that words and pictures are named in different ways. The word-to-picture semantic interference effect cannot readily be understood as the result of activation remaining within a semantic route to word naming. Whether the Stroop picture-word interference and the Lag 3 word-to-picture interference may eventually be interpreted in the same way remains to be seen.

\section{REFERENCES}

BAJo, M.-T. (1988). Semantic facilitation with pictures and words. Journal of Experimental Psychology: Learning, Memory, \& Cognition, 14, 579-589.

BaJo, M.-T., \& Cañas, J. J. (1989). Phonetic and semantic activation during picture and word naming. Acta Psychologica, 72, 105-115.

Balota, D. A., Cortese, M. J., Sergent-Marshall, S. D., Spieler, D. H., \& YAP, M. J. (2004). Visual word recognition of single-syllable words. Journal of Experimental Psychology: General, 133, 283-316.

BALUCH, B., \& BeSNER, D. (1991). Visual word recognition: Evidence for strategic control of lexical and nonlexical routines in oral reading. Journal of Experimental Psychology: Learning, Memory, \& Cognition, 17, 644-652.

Becker, S., Moscovitch, M., Behrmann, M., \& Joordens, S. (1997). Long-term semantic priming: A computational account and empirical evidence. Journal of Experimental Psychology: Learning, Memory, \& Cognition, 23, 1059-1082.

Bub, D., \& Gum, T. (1990). PsychLab (Version 0.85) [Computer software]. Montreal: McGill University.

CAMPBell, J. I. D., \& ClaRK, J. M. (1989). Time course of error priming in number-fact retrieval: Evidence for excitatory and inhibitory mechanisms. Journal of Experimental Psychology: Learning, Memory, \& Cognition, 15, 920-929.

Carr, T. H., McCauley, C., Sperber, R. D., \& Parmelee, C. M. (1982). Words, pictures and priming: On semantic activation, conscious identification, and the automaticity of information processing. 
Journal of Experimental Psychology: Human Perception \& Performance, 8, 757-777.

Chateau, D., \& Lupker, S. J. (2003). Strategic effects in word naming: Examining the route-emphasis versus time-criterion accounts. Journal of Experimental Psychology: Human Perception \& Performance, 29, 139-151.

Coltheart, M., Rastle, K., Perry, C., Langdon, R., \& Ziegler, T. (2001). DRC: A dual-route cascaded model of visual word recognition and reading aloud. Psychological Review, 108, 204-256.

Cycowicz, Y. M., Friedman, D., Rothstein, M., \& Snodgrass, J. G. (1997). Picture naming by young children: Norms for name agreement, familiarity, and visual complexity. Journal of Experimental Child Psychology, 65, 171-237.

Damian, M. F., \& BowERs, J. S. (2003). Locus of semantic interference in picture-word interference tasks. Psychonomic Bulletin \& Review, 10, 111-117.

Damian, M. F., Vigliocco, G., \& Levelt, W. J. M. (2001). Effects of semantic context in the naming of pictures and words. Cognition, 81, B77-B86.

Dean, M. P., Bub, D. N., \& Masson, M. E. J. (2001). Interference from related items in object identification. Journal of Experimental Psychology: Learning, Memory, \& Cognition, 27, 733-743.

Dell, G. S., Schwartz, M. F., Martin, N., Saffran, E. M., \& Gagnon, D. A. (1997). Lexical access in aphasic and nonaphasic speakers. Psychological Review, 104, 801-838.

Durso, F. T., \& Johnson, M. K. (1979). Facilitation in naming and categorizing repeated pictures and words. Journal of Experimental Psychology: Human Learning \& Memory, 5, 449-459.

Ferrand, L., Grainger, J., \& Segui, J. (1994). A study of masked form priming in picture and word naming. Memory \& Cognition, 22, 431-441.

Glaser, W. R. (1992). Picture naming. Cognition, 42, 61-105.

Glaser, W. R., \& DUNGELHOFF, F.-J. (1984). The time course of pictureword interference. Journal of Experimental Psychology: Human Perception \& Performance, 10, 640-654.

Glaser, W. R., \& Glaser, M. O. (1989). Context effects in Stroop-like word and picture processing. Journal of Experimental Psychology: General, 118, 13-42.

Humphreys, G. W., Lloyd-Jones, T. J., \& Fias, W. (1995). Semantic interference effects on naming using a postcue procedure: Tapping the links between semantics and phonology with pictures and words. Journal of Experimental Psychology: Learning, Memory, \& Cognition, 21, 961-980.

Humphreys, G. W., Riddoch, M. J., \& Quinlan, P. (1988). Cascade processes in picture identification. Cognitive Neuropsychology, $\mathbf{5}$, 67-103.

Joordens, S., \& BESNer, D. (1992). Priming effects that span an intervening unrelated word: Implications for models of memory representation and retrieval. Journal of Experimental Psychology: Learning, Memory, \& Cognition, 18, 483-491.

Kroll, J. F., \& Stewart, E. (1994). Category interference in translation and picture naming: Evidence for asymmetric connections between memory representations. Journal of Memory \& Language, 33, 149174.

Levelt, W. J. M., Roelofs, A., \& Meyer, A. S. (1999). A theory of lexical access in speech production. Behavioural \& Brain Sciences, 22, 1-75.

LUPKER, S. J. (1988). Picture naming: An investigation of the nature of categorical priming. Journal of Experimental Psychology: Learning, Memory, \& Cognition, 14, 444-455.

LuPKer, S. J., BROWN, P., \& Colombo, L. (1997). Strategic control in a naming task: Changing routes or changing deadlines? Journal of Experimental Psychology: Learning, Memory, \& Cognition, 23, 570590.

Lupker, S. J., Kinoshita, S., Coltheart, M., \& TAYlor, T. E. (2003). Mixing costs and mixing benefits in naming words, pictures and sums. Journal of Memory \& Language, 49, 556-575.

MACLEOD, C. M. (1991). Half a century of research on the Stroop effect: An integrative review. Psychological Bulletin, 109, 163-203.

Masson, M. E. J. (1991). A distributed memory model of context effects in word identification. In D. Besner \& G. W. Humphreys (Eds.),
Basic processes in reading: Visual word recognition (pp. 264-336). Hillsdale, NJ: Erlbaum.

Masson, M. E. J. (1995). A distributed memory model of semantic priming. Journal of Experimental Psychology: Learning, Memory, \& Cognition, 21, 3-23.

McCauley, C., Parmelee, C. M., Sperber, R. D., \& Carr, T. H. (1980). Early extraction of meaning from pictures and its relation to conscious identification. Journal of Experimental Psychology: Human Perception \& Performance, 6, 265-276.

McKague, M., Pratt, C., \& Johnston, M. B. (2001). The effect of oral vocabulary on reading visually novel words: A comparison of the dual-route-cascaded and triangle frameworks. Cognition, 80, 231262.

Mcleod, P., Shallice, T., \& Plaut, D. C. (2000). Attractor dynamics in word recognition: Converging evidence from errors by normal subjects, dyslexic patients and a connectionist model. Cognition, 74, 91-113.

Monaghan, J., \& Ellis, A. W. (2002). What exactly interacts with spelling-sound consistency in word naming? Journal of Experimental Psychology: Learning, Memory, \& Cognition, 28, 183-206.

Monsell, S., Patterson, K. E., Graham, A., Hughes, C. H., \& MilROY, R. (1992). Lexical and sublexical translation of spelling to sound: Strategic anticipation of lexical status. Journal of Experimental Psychology: Learning, Memory, \& Cognition, 18, 452-467.

Moore, C. J., \& Price, C. (1999). Three distinct ventral occipitotemporal regions for reading and object naming. Neurolmage, 10, 181-192.

NeELY, J. H. (1991). Semantic priming effects in visual word recognition: A selective review of current findings and theories. In D. Besner \& G. W. Humphreys (Eds.), Basic processes in reading: Visual word recognition (pp. 264-336). Hillsdale, NJ: Erlbaum.

Nelson, D. L., Reed, V. S., \& McEvoy, C. L. (1977). Learning to order pictures and words: A model of sensory and semantic coding. Journal of Experimental Psychology: Learning, Memory, \& Cognition, 3, 485-497.

PACHELla, R. G. (1974). The interpretation of reaction time in informationprocessing research. In B. H. Kantowitz (Ed.), Human information processing: Tutorials in performance and cognition (pp. 41-82). Hillsdale, NJ: Erlbaum.

Posner, M. I., \& SNyder, C. R. R. (1975). Attention and cognitive control. In R. L. Solso (Ed.), Information processing and cognition: The Loyola symposium (pp. 55-85). Hillsdale, NJ: Erlbaum.

RAAIJMAKERS, J. G. W. (2003). A further look at the "language-as-fixedeffect fallacy." Canadian Journal of Experimental Psychology, 57, 141-151.

Raaijmakers, J. G. W., Schrijnemakers, J. M. C., \& Gremmen, F. (1999). How to deal with "the language-as-fixed-effect fallacy": Common misconceptions and alternative solutions. Journal of Memory \& Language, 41, 416-426.

Raman, I., Baluch, B., \& Besner, D. (2004). On the control of visual word recognition: Changing routes versus changing deadlines. Memory \& Cognition, 32, 489-500.

Roelofs, A. (2004). Seriality of phonological encoding in naming objects and reading their names. Memory \& Cognition, 32, 212-222.

Seidenberg, M. S., \& McClelland, J. L. (1989). A distributed developmental model of word recognition and naming. Psychological Review, 96, 523-568.

Shibahara, N.,Zorzi, M., Hill, M. P., Wydell, T., \& Butterworth, B. (2003). Semantic effects in word naming: Evidence from English and Japanese Kanji. Quarterly Journal of Experimental Psychology, 56A, 263-286.

Smith, M. C., \& Magee, L. E. (1980). Tracing the time-course of pictureword processing. Journal of Experimental Psychology: General, 109, 373-392.

SnODGRASS, J. G., \& VANDERWART, M. (1980). A standardized set of 260 pictures: Norms for name agreement, image agreement, familiarity and visual complexity. Journal of Experimental Psychology: Human Learning \& Memory, 6, 174-215.

Southwood, M. H., \& Chatterjee, A. (1999). The interaction of multiple routes in oral reading: Evidence from dissociations in naming and oral reading in phonological dyslexia. Brain \& Language, 72, 14-39. 
Strain, E., Patterson, K., \& Seidenberg, M. S. (2002). Theories of word naming interact with spelling-sound consistency. Journal of Experimental Psychology: Learning, Memory, \& Cognition, 28, 207-214.

TABossi, P., \& LAGHI, L. (1992). Semantic priming in the pronunciation of words in two writing systems: Italian and English. Memory \& Cognition, 20, 303-313.

TAYLOR, T. E., \& LUPKER, S. J. (2001). Sequential effects in naming: A time-criterion account. Journal of Experimental Psychology: Learning, Memory, \& Cognition, 27, 117-138.

Theios, J., \& Amrhein, P. C. (1989). Theoretical analysis of the cognitive processing of lexical and pictorial stimuli: Reading, naming, and visual and conceptual comparisons. Psychological Review, 96, 5-24.

Thompson-Schill, S. L., Kurtz, K. J., \& Gabrieli, J. D. E. (1998). Effects of semantic and associative relatedness on automatic priming. Journal of Memory \& Language, 38, 440-458.

Tree, J. J., \& Hirsh, K. W. (2003). Sometimes faster, sometimes slower: Associative and competitor priming in picture naming with young and elderly participants. Journal of Neurolinguistics, 16, 489-514.

Vitkovitch, M., \& Humphreys, G. W. (1991). Perseverant naming errors in speeded picture naming: It's in the links. Journal of Experimental Psychology: Learning, Memory, \& Cognition, 17, 664-680.

Vitkovitch, M., \& Rutter, C. (2000). The effects of response stimuli interval on error priming in sequential object naming. Visual Cognition, 7, 645-670.

Vitkovitch, M., Rutter, C., Begum, R., \& Thomson, L. (2002). Semantic interference from word primes during picture naming. Paper presented at the British Psychological Conference, Cognitive Psychology Section, Kent, U.K.

Vitkovitch, M., Rutter, C., \& Read, A. (2001). Inhibitory effects during object name retrieval: The effect of interval between prime and target on picture naming responses. British Journal of Psychology, 92, 483-506.

WhEELdON, L. R., \& Monsell, S. (1994). Inhibition of spoken word production by priming a semantic competitor. Journal of Memory \& Language, 33, 332-356.

\section{NOTES}

1. There is a debate as to whether the phonological representations of semantic competitors are activated during target picture naming, as a cascade or an interactive model of processing would imply (e.g., Dell et al., 1997; Humphreys et al., 1988). By contrast, the model of Levelt et al. (1999) maintains that processing is discrete between the two stages of name retrieval (lemma and lexeme). However, it remains a possibility that the target picture activates the phonological representations of semantic competitors, including the prime.

2. A neckband with a microphone was used for the first few participants, but this became faulty and so was replaced by the handheld microphone.
3. Raaijmakers, Schrijnemakers, and Gremmen (1999) have argued that it is unnecessary to carry out item analyses when materials are counterbalanced across conditions (see also Raaijmakers, 2003). We can report, though, that item analyses in both experiments were carried out and that the critical interactions between prime relatedness and target type were significant.

APPENDIX

Experiment 2: Prime and Target Stimuli

\begin{tabular}{|c|c|c|c|}
\hline Prime & Target & Prime & Target \\
\hline \multicolumn{2}{|c|}{ List A } & \multicolumn{2}{|c|}{ List $\mathrm{C}$} \\
\hline kettle & toaster & ostrich & peacock \\
\hline ant & spider & comb & toothbrush \\
\hline clock & watch & hammer & axe \\
\hline guitar & trumpet & bicycle & motorcycle \\
\hline boat & truck & pig & rhinoceros \\
\hline mouse & squirrel & dog & fox \\
\hline giraffe & zebra & piano & harp \\
\hline shoe & boot & shirt & jumper \\
\hline cherry & strawberry & banana & pineapple \\
\hline spoon & fork & jug & vase \\
\hline gun & cannon & fridge & stove \\
\hline knife & scissors & flag & kite \\
\hline \multicolumn{2}{|c|}{ List B } & \multicolumn{2}{|c|}{ List D } \\
\hline cow & horse & drum & bell \\
\hline cup & glass & elephant & camel \\
\hline belt & tie & apple & pear \\
\hline horn & violin & sock & glove \\
\hline star & moon & window & door \\
\hline spanner & pliers & nail & screw \\
\hline aeroplane & helicopter & table & stool \\
\hline owl & eagle & frog & turtle \\
\hline deer & goat & thimble & spool \\
\hline trousers & dress & chicken & duck \\
\hline chair & couch & flower & leaf \\
\hline onion & pumpkin & ashtray & pipe \\
\hline
\end{tabular}

(Manuscript received October 8, 2002; revision accepted for publication April 11, 2005.) 